\title{
Optimal Rules of Negligent Misrepresentation in Insurance Contract Law
}

\author{
Lando, Henrik
}

\author{
Document Version \\ Accepted author manuscript \\ Published in: \\ International Review of Law and Economics
}

DOI:

10.1016/j.irle.2016.02.002

Publication date:

2016

License

CC BY-NC-ND

Citation for published version (APA):

Lando, H. (2016). Optimal Rules of Negligent Misrepresentation in Insurance Contract Law. International Review of Law and Economics, 46, 70-77. https://doi.org/10.1016/j.irle.2016.02.002

Link to publication in CBS Research Portal

\section{General rights}

Copyright and moral rights for the publications made accessible in the public portal are retained by the authors and/or other copyright owners and it is a condition of accessing publications that users recognise and abide by the legal requirements associated with these rights.

\section{Take down policy}

If you believe that this document breaches copyright please contact us (research.lib@cbs.dk) providing details, and we will remove access to the work immediately and investigate your claim.

Download date: 26. Apr. 2023

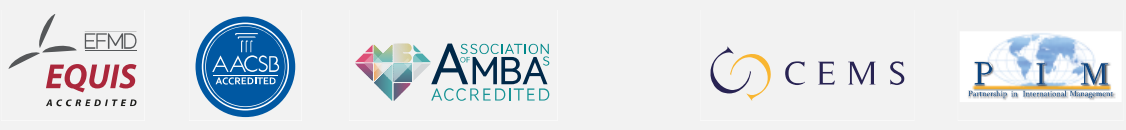




\section{Optimal Rules of Negligent Misrepresentation in Insurance Contract Law}

\section{Henrik Lando}

Journal article (Post print version)

CITE: Optimal Rules of Negligent Misrepresentation in Insurance Contract Law. / Lando, Henrik. In: International Review of Law and Economics, Vol. 46, 06.2016, p. $70-77$.

DOl: 10.1016/j.irle.2016.02.002

Uploaded to Research@CBS: June २०17

(C) 2017. This manuscript version is made available under the CC-BY-NC-ND 4.0 license http://creativecommons.org/licenses/by-nc-nd/4.0/ 


\title{
OPTIMAL RULES OF NEGLIGENT MISREPRESENTATION IN INSURANCE LAW
}

\author{
HENRIK LANDO \\ DEPARTMENT OF LAW \\ EMAIL: HL.JUR@CBS.DK
}

\begin{abstract}
Rules of misrepresentation in insurance contract law differ widely between jurisdictions. When the insured has negligently misrepresented a fact prior to contracting, common law allows the insurer to rescind the contract if the misrepresentation was material, while civil law countries apply more lenient rules. The article compares the efficiency of the common and the civil law rules in an adverse selection model in which the insurer separates types of risk not only through a deductible but also by requiring the insured to represent their type. A strict rule of misrepresentation increases the incentive for policy-holders to represent truthfully but also exposes them to risk when they may misrepresent by mistake. While the economic literature has tended to defend the strict common law rule, because it makes it easier for the insurer to separate types, the present article demonstrates that the more lenient civil law rules may be more efficient, especially when the cost for the insurer of auditing types is low.
\end{abstract}




\section{INTRODUCTION}

When a policyholder presents a claim under an insurance policy, the insurer sometimes audits the claim and finds that the insured pre-contractually misrepresented a fact relevant to her ${ }^{1}$ risk. If the insurer can prove that the insured did so intentionally in order to obtain a lower premium, all legal systems allow the insured to rescind the contract. If, however, the insurer cannot establish sufficient proof of intent, if e.g. the insured may have remembered the fact incorrectly, or may have been wrongly informed of her risk, consequences differ widely between legal systems. ${ }^{2}$ For such misrepresentation, termed negligent, common law allows for a rescission of the contract if only misrepresentation was 'material', ${ }^{3}$ whereas the German Insurance Contract Act (2008) does not allow the insurer to reduce the indemnity at all. ${ }^{4}$ As an intermediate rule, some civil law countries ${ }^{5}$ apply the pro rata rule, which restricts coverage to what the paid premium would have secured if the insured had represented her type correctly.

These rules are all controversial. In the $\mathrm{US}^{6}$, critics of the common law rule have pointed to the unreasonableness of cases such as Henwood v. Prudential Insurance ${ }^{7}$ where a woman had seen a psychiatrist for emotional problems when she was a teenage, and later before taking out life insurance had denied having any 'nervous or mental disorder'. Although her death in a car accident was unrelated to the misrepresented fact, the contract was voided by the court. In Germany, the lenient rule has been said to not sufficiently discourage fraud ${ }^{8}$ that constitutes a significant problem for some insurance markets. ${ }^{9}$

In this debate, the economic literature, e.g. Dixit (2000), Gravelle (1991), and Picard (2009), has tended to favour the strict common law rule, arguing that it enables effective separation of risk types and expands the set of parameters for which an equilibrium exists. $^{10}$ The present article argues, in contrast, that the more lenient of two rules may be more efficient when the insured may misrepresent by mistake, in particular when the cost for the insurer of auditing is low. This may appear obvious, since the insurer must be less risk averse than the insured (otherwise there would be no reason for the contract), and one would therefore expect it to be optimal for the insurer to bear the risk of inadvertent

\footnotetext{
${ }^{1}$ For convenience, the insured is female and the insured male in this article.

${ }^{2} \mathrm{So}$, in fact, do the legal consequences when the insured can prove that the misrepresentation was an honest, non-negligent mistake. In the model of the present article, it is clearly inoptimal to allow for a rescission in this case.

${ }^{3} \mathrm{~A}$ misrepresentation is material when the insurer would not have entered the contract on its given terms if there had been no misrepresentation; if this condition is met, the insurer can even void the contract in case of honest misrepresentation

${ }^{4}$ Except when the insured is found to have acted in a grossly negligent manner, see below for a closer description of the rules.

${ }^{5}$ See Tarr and Tarr (2001)

${ }^{6}$ Barnes (2011) gives an overview of the American academic debate.

${ }^{7} 64$ D.L.R. (2d) 715, S.C.C., 1967. This example is mentioned by Rea (2003).

${ }^{8}$ This criticism is mentioned by Heiss $(2013$

${ }^{9}$ See e.g. Derrig (2002).

${ }^{10}$ Rothschild-Stiglitz (1976) demonstrated that one cannot be certain that there exists a Nash-equilibrium in the insurance market under adverse selection.
} 
mistakes on the part of the insured. However, if the insurer can commit to an auditing strategy, he can undo the strictness of a rule by lowering the probability of auditing, and thereby save on auditing costs. It is therefore not obvious that a lenient rule can be better than a strict rule. Yet, when the cost of auditing is low it will be shown to be more efficient, for reasons to be explained, that the insurer audits often and applies a low sanction to misrepresentation than that he audits rarely and applies a high sanction. Likewise, for the case where the insurer cannot commit to a level of auditing, it will be shown that a strict rule can provide too strong an incentive to audit ex post when the claim is raised, and that too much auditing may create greater inefficiencies than too little or no auditing which may be the result of a lenient rule.

Before introducing the model, the following sections offer a more detailed description and illustration of the legal rules, and a review of the literature.

\section{The Legal Rules}

The main rules concerning negligent misrepresentation are in decreasing order of strictness: the common law rule, the contribute-to-the-loss or causation rule, the pro rata rule, the pro rata rule requiring causation, the recovery rule, and the German rule.

The common law rule allows rescission for 'material misrepresentation', regardless of whether it is innocent, negligent or intentional. As mentioned, misrepresentation is said to be material when a reasonable insurer would not have issued the insurance on its given terms had he known the misrepresented fact. ${ }^{11}$ It should be mentioned that the rule is not universally applied in the US, as some States have statutorily limited reduction of coverage to cases of intentional or reckless misrepresentation (see American Law Institute, Tentative Draft, 2013, p. $84(\mathrm{~h})$ ), and that it is no longer the rule applied in England for consumer insurance contracts, for which the Consumer Insurance (Disclosure and Representations) Act 2012 now applies the pro rata rule to negligent (but not reckless) misrepresentation. ${ }^{12}$

The contribute-to-the-loss rule covers fully if the unstated or misrepresented fact was irrelevant to the insurance event but not at all when the fact caused the event. The concept of causation can take different meanings. In German law, it is taken to mean that the misrepresented fact had some influence on the event, see Heiss (2013). ${ }^{13}$

The pro rata rule applies in several countries (e.g. Denmark $)^{14}$ and sets the indemnity equal to what the paid premium would have secured if there had been no misrepresentation ${ }^{15}$. If the premium would have been twice as high, the indemnity is reduced to $50 \%$. If the insurer would have altered the terms in some other way, those altered terms apply; thus, if

\footnotetext{
${ }^{11}$ There is also a requirement that the actual insurer reasonably relied on the stated fact, i.e. that he would (reasonably) not have entered the terms of the contract on its given terms if he had known the true fact. See The American Law Institute (2015) $\S 8$ and $\S 9$.

${ }^{12}$ See http://www.legislation.gov.uk/ukpga/2012/6/contents. See also Ruehl (2006) for how German and English rules differed less in reality than in the books even before the new English rule.

${ }^{13}$ It may therefore be better, as done by ALI, to use the term contribute-to-the-loss rather than causation.

${ }^{14}$ See Tarr and Tarr (2001).

${ }^{15}$ The Danish Insurance Contract Act (1930), §6.
} 
the insurer would have excluded accidents resulting from a nervous condition if the insured had admitted to suffering from this condition, the insurer shall not pay in case of such accident.

The combination of the pro rata rule and the contribute-to-the-loss rule, which is suggested in the Principles of European Insurance Contract Law (PEICL, 2009) for negligent misrepresentation, and applied in Germany for grossly negligent misrepresentation, requires causation for there to be reduction in cover, but then reduces the indemnity only pro rata. The recovery rule, as proposed in a draft from the American Law Institute ${ }^{16}$ allows the insurer to reduce the indemnity by the extra premium which the insured would have paid in case of correct disclosure.

As mentioned, the German rule allows no reduction for negligent misrepresentation.

It is worth noting that these rules concerning negligent misrepresentation are supplemented by rules that apply to innocent, grossly negligent, reckless or intentional misrepresentation. To judge the strictness and working of any two sets of rules, the adjacent rules must also be considered, as must the standard of proof required for showing mainly grossly negligent, reckless or intentional misrepresentation. For example, when comparing the strictness of the German rule and the ALI draft proposal (2013), it is worth noting that if the insured has misrepresented in a grossly negligent manner, the pro rata rule requiring causation applies in Germany, whereas in the ALI draft proposal, the insurer can void the contract in case of reckless misrepresentation. ${ }^{17}$ Whether this means that the ALI proposal is stricter than the German rules cannot be decided without knowing the standard of proof applied to recklessness in the ALI proposal (namely the same as that applied to fraudulent misrepresentation under applicable state law, see §7.4) and the standard applied to grossly negligent misrepresentation under German law.

Moreover, a full comparison of the sets of rules would involve other aspects by which the rules differ, such as the conditions under which the insurer can cancel a policy prospectively in case of either innocent, negligent, grossly negligent or reckless misrepresentation.

2.1. An illustration of the rules. To gain an impression of the relative strictness of the rules, we now compare what pay-outs would be under the different rules for the woman whose contract was voided in the example above, if we assume that her report amounted to negligent misrepresentation. We can assume, for the sake of illustration, that the woman's emotional problems were in fact severe and that her probability of dying before a certain age was $6 \%$, whereas for other women resembling her in other respects but without emotional problems, the same probability would be only 4\%. We can also set the indemnity at 100 and assume, to simplify, that the insurers always audit the insured's type when the insured presents a claim. Under these assumptions, we can consider the possibility that the insurers offer two contracts: one at a premium of 4 for the women of low risk, and the other at a

\footnotetext{
${ }^{16}$ American Law Institute, Tentative Draft, 2013. The proposal for harmonisation was issued before the ALI's project on insurance contract law turned into a Restatement project.

${ }^{17}$ Which according to $\S 7.4$ applies not only to indifference concerning the truth of a statement but also to cases where proof of fraudulent misrepresentation is difficult.
} 
premium of 6 for the high risk, and we can ask what the consequences would be for the woman under the different rules if she would choose the contract intended for the low risk although her risk was in fact high. In particular, it is of interest whether the woman would have had an incentive to do so if she had known her risk to be high.

Under the common law rule the pay-out in case of death would be only the premium paid; it must be repaid in case of rescission, since the performances of both parties must be undone. This would yield an expected pay-out of $4 \times 0.06=0.24$. It goes without saying that the common law rule would deter the woman from misrepresenting when auditing is certain.

Under the pro rata rule, if discovered to have misrepresented, the woman would receive a pay-out based on the following equation:

$$
\frac{\text { pay }- \text { out }}{100}=\frac{\text { premium if truth not reported }}{\text { premium if truth reported }}=\frac{4}{6}
$$

The pay-out would hence be 66.6, which would deter the woman from misrepresenting, since she would effectively be buying insurance at a premium of 4 with an indemnity of 66.6, which would amount to under-insurance at an actuarially fair price, since the expected pay-out would be $66.6 \times 6=4$, equal to the premium. She would prefer full insurance at the fair price.

Under the contribute-to-the-loss rule, if the woman would choose the contract for the low risk, she would have zero indemnity in case of death caused by her emotional problems and she would receive a full pay-out otherwise, which means that she would receive full indemnity in the actual case where death was caused by a traffic accident. There would be causation with a probability of $6 \%-4 \%$, since death would occur with a probability of $4 \%$, even in the absence of emotional problems, so the effective contract would pay-out 100 with probability $4 \%$ and 0 with probability $2 \%$. The expected pay-out would be 4 , as under the pro rata rule. Again, this would deter the risk averse woman, since she would rather pay the difference in premium of 2 to be covered also in the event of causation, which occurs with a probability of $2 \%$. Note that both the pro rata and the contribute-to-the-loss rule are actuarially fair in case of misrepresentation if auditing is certain to occur. This means that the pro rata rule dominates the contribute-to-the-loss rule in the example, in the following sense. If the woman did not consider herself to have suffered from mental problems but thought that there might be a possibility that the court would find otherwise, she would prefer the pro rata rule which involves less risk (the contribute-to-the-loss rule is a mean-preserving spread of the pro rata rule), while the insurer would be indifferent between the two rules that yield him the same expected pay-off.

Under the pro rata rule which requires causation, the pay-out would be 100 with a probability of $4 \%$ (there is no causation) and then 66.6 with a probability of $2 \%$. This would yield an expected pay-out of 5.32 , considerably larger than the premium of 4 . The woman would be deterred only if strongly risk averse.

Under the recovery rule, the indemnity would be reduced by the too low premium, so 98 would be paid out in case of death, that is with a probability of $6 \%$. This would yield an expected pay-out of 5.88. Note that there would be no incentive for the woman to report 
truthfully under the recovery rule, as not reporting represents a $94 \%$ probability of not paying the extra premium of 2 .

\section{The Literature}

This article builds on Dixit (2000), Dixit and Picard (2003), and Picard (2009). Dixit (2000) pointed out how voidance due to intentional misrepresentation by the insured mitigates the problem identified by Stiglitz and Rothschild (1976) that adverse selection may lead to non-existence of competitive equilibrium when the number of high risks is low. Furthermore, Dixit (2000) demonstrated that the common law rule leads to a Paretoimprovement of the equilibrium when it exists. Dixit's assumption that the insurer can commit to a random investigation policy was relaxed in Picard (2009), while his assumption that the insured always knows her own characteristics was relaxed in Dixit and Picard (2003).

The present paper builds particularly on the latter, which assumed that the insured receives a noisy signal about her true type, and that the insurer can choose to verify (audit) either the type, the signal or both. It characterised the optimal auditing strategy, derived certain properties of the equilibrium contracts, and demonstrated that the common law rule is optimal if the probability for the insured of having received a false signal is sufficiently low. Moreover, for the case in which the insured is found to have misrepresented, it asked who of the parties should produce evidence concerning the signal received by the insured, i.e. who should bear the burden of proof of whether misrepresentation was intentional (bad faith) or innocent (good faith). ${ }^{18}$

The present analysis differs from Dixit and Picard (2003) in terms of its main aim. They did not aim to compare the different legal rules, although they derived one result that can be used in such a comparison, namely the result that the common law rule is optimal when the signal is sufficiently informative.

In an earlier, original, article Gravelle (1991) anticipated some of Dixit and Picard's results but in a somewhat different setting. Gravelle assumed that applicants for insurance differ in the disutility they obtain from being dishonest, and he assumed the probability of auditing to be exogenously fixed (in an earlier version he analysed a more complicated model in which the insurer could decide to spend more or less money on auditing (see footnote 18, page 33)). He demonstrated that an insured who knows she may be mistaken about her type may nevertheless agree to an insurance contract that involves a strict sanction in case of misrepresentation because such a contract may deter dishonest types from dissembling and its premium may thereby be lower. Intervention in the market may conceivably lower welfare even in a setting where the insured are ignorant of insurance law, due to the higher

\footnotetext{
${ }^{18}$ The authors proved that when the cost to the insurer of verifying the insured's bad faith is equal to the cost to the insured of verifying her good faith, the burden of proof should be on the insurer because the cost for the insured of proving her innocence is one that she cannot insure against. Only if the cost to the insured is lower than the cost to the insurer by some margin should the burden of proof be on the insured.
} 
degree of cross-subsidisation (honest types paying for dishonest types) under a lenient rule. Finally, there exists a body of legal literature that cannot be reviewed here. ${ }^{19}$

\section{THE ModeL}

The model can be briefly outlined as follows. Applicants for insurance are assumed to be of either high or low risk. Each applicant receives either a bad signal that she is high risk or a good signal that she is low risk. If she receives a good signal, it might be wrong; she might in reality be a high risk. ${ }^{20}$ Despite of this possibility, it is in the interest of the competing insurers to attract the recipients of the good signal by offering them a contract which is unattractive to the recipients of the bad signal; the premium of such a contract can be low exactly because the contract is not chosen by the recipients of the bad signal. The contract may be unattractive to the recipients of the bad signal by either not covering fully, i.e. by containing a deductible, or by requiring the insured to represent her type. To the extent that the insurer audits the policy-holder's type when she presents a claim, and to the extent that the (mandatory) legal rule of misrepresentation then reduces the pay-out, the recipients of the bad signal will find it unattractive to misrepresent. While a strict rule is hence desirable from an incentive viewpoint, it exposes the insured who may misrepresent by mistake to risk. The question is how this trade-off between incentives and risk allocation plays out when the insurer may or may not be able to commit to a level of auditing. This is not a straightforward trade-off between incentives and risk allocation because a strict rule allows the insurer to lower the level of auditing, and a lower level of auditing reduces the risk to the insured who may have misrepresented by mistake.

The model differs from that of Dixit and Picard (2003) in mainly three respects. They assumed that the signal can be observed directly, that the insurer may offer a higher pay-out when the insured is revealed to have received a signal that she is a low risk than when there is no auditing, and that the pay-out may exceed the insured's loss. The first assumption is dropped here because such signal verification appears to be rare in case law, perhaps because lapses of memory are often the cause of misrepresentation or because the cost of signal verification tends to be high or even prohibitive. The second is dropped because we do not seem to observe policies that distinguish pay-outs in this manner, perhaps because doing so would provide an incentive for the insurer not to reveal that he investigated the insured's type, and the third is dropped because overcompensation is not enforced or not allowed (in some jurisdictions at least ${ }^{21}$ ) due to moral hazard concerns, unless the insurance is for a fixed sum as in life or personal accident insurance where moral hazard is of less concern.

The model is now introduced in more detailed notation, summarised in Appendix A.

\footnotetext{
${ }^{19}$ As mentioned above, Barnes (2010) provides an overview of the legal literature critical of the common law rule.

${ }^{20}$ For simplicity, if she receives a bad signal, she knows her risk to be high.

${ }^{21}$ For example, $\$ 39$ in the Danish Insurance Contract Act stipulates that if the insurance contract specifies a greater pay-out than the insurer's loss, the insurer is under no obligation to pay out the greater amount.
} 
A continuum of risk-averse applicants wish to insure against a potential loss of $L$. The fraction $\lambda$ of applicants are high risk, i.e. their probability of an accident involving the loss is $\pi_{h}$ while the other applicants face a lower risk of probability $\pi_{l}$. Among the high risk, a fraction $q$ receives a wrong signal that they are low risk, while the fraction $1-q$ receives a correct signal that they are high risk. As mentioned, the low risks all receive a correct signal. ${ }^{22}$ Those who receive a signal that they are high (low) risk are termed $h$-recipients ( $l$-recipients.) The $l$-recipients know that their signal may not be trustworthy.

At the first stage of the game $n$ insurers, where $n$ is large, offer two (possibly identical) contracts: ${ }^{23} C_{l}$ intended for the $l$-recipient, and $C_{h}$ intended for the $h$-recipient. Both contracts stipulate a premium and an indemnity, and when the insurer can commit to a level of auditing the $C_{l}$ contract also includes an auditing probability $p$. At the second stage, each applicant chooses between the two contracts or may choose not to take up insurance. ${ }^{24}$ In the third stage, an accident may occur, in which case the insured presents a claim and may be audited with the pre-stated probability in the case of commitment and with the ex-post profit maximising probability in the absence of commitment. If the insured is found to have misrepresented, coverage is reduced according to the mandatory legal rule. Contrary to Dixit and Picard (2003), if the insured is found to be low risk, coverage is assumed to be the same as if there had been no auditing, as mentioned in the section describing the literature above.

\section{Definitions of a FEASible ALLOCATION AND OF AN EQUiLibrium}

An allocation $A=\left(C_{l}, C_{h}\right)$ is feasible if insurers make non-negative profits from offering the two contracts, if the $l$-recipient prefers the $C_{l}$ contract to the $C_{h}$ contract and to no contract, and if the $h$-recipient prefers the $C_{h}$ contract to the $C_{l}$ contract and to no contract. A feasible allocation is a competitive equilibrium when an insurer cannot deviate by offering another allocation that will yield greater profits when the policyholders respond to the new offer in an optimal manner. ${ }^{25}$ It is a well-known result in Rothschild and Stiglitz (1976) that an equilibrium must be separating; as shown by Dixit and Picard (2003), this result holds also in the present setting, since a pooling equilibrium is more unstable when insurers have two instruments of separation available to them rather than only one. Moreover, the

\footnotetext{
${ }^{22}$ The analysis would become more complicated if those who are low risk might receive a signal that they are not, i.e. if the possibility of a false negative was included in the analysis. Since the legal rule itself does not affect the incentive of those who receive a negative signal to act on the assumption that it might be wrong, the possibility of a false negative is left out of the present analysis.

${ }^{23}$ Rothschild and Stiglitz (1976) only allowed each insurer to offer one contract. Allowing an insurer to offer more than one contract exacerbates the existence problem, but does not change the nature of the equilibria, see Picard (2009, p.869).

${ }^{24}$ The case where the insured randomise between the two contracts turns out to be of interest mainly in the analysis of the case in which the insurer cannot commit to an auditing strategy.

${ }^{25}$ The equilibrium is hence sub-game perfect; for a more elaborate description of the equilibrium, see Picard (2009).
} 
contract offered to the $h$-recipient in the separating equilibrium must be fully covering at an actuarially fair premium, i.e. $\tilde{C}_{h}=(\bar{k}, \bar{I})$. There is no reason to distort the contract for the $h$-recipient. This contract meets the $h$-recipient's participation constraint which hence does not have to be included in the maximisation problem below. Also, due to competition, the profit on the $C_{l}$ contract must be zero. These constraints imply that the contract offered to the $l$-recipients in equilibrium must maximise the expected utility of the $l$-recipient among the $C_{l}$ contracts which, when offered together with $\tilde{C}_{h}=(\bar{k}, \bar{I})$, will not be chosen by the $h$-recipients and will yield zero profits. Hence, if an equilibrium exists, the equilibrium contract $\tilde{C}_{l}=(\tilde{k}, \tilde{I}, \tilde{p})$ must maximise the expected utility of the $l$-recipient:

$$
(1-\hat{\pi}) U\left(w_{0}-k\right)+\hat{\pi} \beta p U\left(w_{0}-L+\nu\right)+\hat{\pi}(1-\beta p) U\left(w_{0}-L+I\right)
$$

subject to a non-negative profit condition on the $C_{l}$ contract:

$$
k-\alpha \pi_{h} p(\nu+k)-\left((1-\alpha) \pi_{l}+(1-p) \alpha \pi_{h}\right)(I+k)-\hat{\pi} p c \geq 0
$$

subject to the truth-telling constraint:

$$
U\left(w_{0}-\bar{k}\right) \geq\left(1-\pi_{h}\right) U\left(w_{0}-k\right)+\pi_{h} p U\left(w_{0}-L+\nu\right)+\pi_{h}(1-p) U\left(w_{0}-L+I\right)
$$

and subject to the constraints:

$$
\begin{array}{r}
0 \leq p \leq 1 \\
0 \leq I \leq L-k
\end{array}
$$

In (1), $(1-\hat{\pi}) U\left(w_{0}-k\right)$ is the expected utility from no accident occurring; $\hat{\pi} \beta p U\left(w_{0}-L+\nu\right)$ arises when an accident occurs, the type is high risk and is audited; and $\hat{\pi}(1-\beta p) U\left(w_{0}-\right.$ $L+I)$ arises when an accident occurs, and the type is either not audited or, if audited, is not high risk.

In (2), $\alpha \pi_{h} p$ is the probability that the $l$-recipient is high risk, will suffer an accident and will be audited, and $(1-\alpha) \pi_{l}+(1-p) \alpha \pi_{h}$ is the probability that the $l$-recipient will either be low risk and will suffer an accident (in which case it does not matter whether there is auditing or not) or will be high risk, will suffer an accident but will not be audited.

In (3), $\left(1-\pi_{h}\right) U\left(w_{0}-k\right)$ is the expected utility from when no accident occurs; $\pi_{h} p U\left(w_{0}-\right.$ $L+\nu)$ is the expected utility from when an accident occurs, the type is audited, and coverage is reduced according to the legal rule; $\pi_{h}(1-p) U\left(w_{0}-L+I\right)$ is the expected utility from when an accident occurs and no auditing is carried out; and $U\left(w_{0}-\bar{k}\right)$ is the utility from choosing the contract intended for the $h$-recipient.

It is not necessary to include the $l$-recipient's participation constraint in the maximisation problem, because the $C_{l}$ contract which maximises the expected utility of the $l$-recipient must yield the $l$-recipient at least her outside option, which we assume to be no contract. This is so because the insurer could offer the equivalent of no contract, namely the contract that pays out zero at a premium of zero. This contract would respect the truth-telling constraint, the $l$-recipient's participation constraint and the zero-profit condition, so when it is not chosen in equilibrium, the $l$-recipient must be made at least as well off as she would be under this zero contract. 
It follows that when comparing the efficiency of two rules, $\nu_{1}$ and $\nu_{2}$, we can compare the expected utility of the $l$-recipient in the competitive equilibrium under each rule, when such an equilibrium exists. In any separating equilibrium, the $h$-recipient always gets the undistorted, actuarially fair contract, and the insurers always get zero profits, so if the $l$-recipient is better off under $\nu_{1}$ than under $\nu_{2}, \nu_{1}$ Pareto-dominates $\nu_{2}$.

Before turning to the comparison of the l-recipient's contract under the different rules, it is worth understanding how the insurers will separate the two types in the present model, and how this optimal policy differs from that of Rothschild and Stiglitz (1976) and Dixit and Picard (2003).

\section{On the Use of Deductibles AND REPRESENTATION IN EQUILIBRium}

Rothschild and Stiglitz (1976) demonstrated that the $C_{l}$ contract should always include a deductible. A deductible can serve as an effective means of separation because it comes at a higher cost to the $h$-recipient than to the $l$-recipient as the $h$-recipient will have to pay it more often than the $l$-recipient if the $h$-recipient chooses the $C_{l}$ contract. In the current setting, by contrast, when auditing is sufficiently frequent the $h$-recipient will pay the deductible less often than the $l$-recipient, if the $h$-recipient chooses the $C_{l}$ contract, because the $h$-recipient will then receive $\nu$ when an accident occurs. Concretely, if the $h$-recipient chooses the $C_{l}$ contract, her net pay-out will be $I$ with probability $\pi_{h}(1-p)$ while for the $l$-recipient the net pay-out will be $I$ with probability $\hat{\pi}(1-p \beta)$, where $\beta$ is the probability for the $l$-recipient of being a high risk conditional on an accident. When $p$ is close to one, $\pi_{h}(1-p)<\hat{\pi}(1-p \beta)^{26}$, such that a lowering of $I$ will affect the $l$-recipient more than the $h$-recipient. This sheds light on the result, derived in Appendix B by Lagrange optimisation, that if there exists an equilibrium, it will be one of under-insurance $(I+k<L)$ for the $l$-recipient if and only if

$$
\frac{\pi_{h}(1-p)}{\hat{\pi}(1-p \beta)}>\frac{\left(1-\pi_{h}\right)}{(1-\hat{\pi})}
$$

This condition may not be fulfilled if $p$ is high and $\beta$ is low. A high $p$ and a low $\beta$ may occur in equilibrium, when $\alpha$ and $c$ are both low, since a high level of auditing is then neither costly to the $l$-recipient (due to the low $\alpha$ ) nor costly in terms of auditing costs (due to the low $c$ ), and since a low $\alpha$ in itself insures a low $\beta$. In contrast, when $c$ is sufficiently high, $p$ will be zero ${ }^{27}$, in which case separation will occur only through the deductible. In conclusion, there may be equilibria in which the types of risk are separated through representation only, through a deductible only, or through both instruments.

\section{Comparison of RUles}

A rule $\nu_{1}$ will be said to weakly Pareto-superior a rule $\nu_{2}$ if when there exists a competitive equilibrium under the rule $\nu_{2}$ then there also exists a competitive equilibrium under the

\footnotetext{
${ }^{26}$ This can be seen by noting that the derivative of $\frac{(1-p \beta)}{(1-p)}$ converges to infinity for $p$ converging to 1 .

${ }^{27}$ Consider 22]; if $c$ is very high and $p$ and $\hat{\pi}$ are positive, the $C_{l}$ contract cannot make a positive profit with auditing
} 
rule $\nu_{1}$, and the equilibrium under rule $\nu_{1}$ Pareto-dominates the equilibrium under rule $\nu_{2}$. The term weakly refers to the fact that an equilibrium may not exist under either rule, in which case the rules cannot be compared. It will first be assumed that the insurer can commit to an auditing strategy; for this case we consider the role of the cost of auditing and of the informativeness of the signal.

\subsection{When the insurer can commit to an auditing probability.}

Proposition 1. When the insurer can commit to an auditing strategy and the cost of auditing is sufficiently small, the more lenient of two rules is weakly Pareto-superior, if it induces truth-telling when auditing is certain to occur

The proof, which is explained in some detail below and further spelled out in Appendix $\mathrm{C}$, demonstrates that if there exists a competitive equilibrium under the stricter rule, then there exists a feasible allocation under the more lenient rule which Pareto-dominates the equilibrium under the stricter rule. This in turn implies that there exists a competitive equilibrium under the more lenient rule and that it Pareto-dominates the competitive equilibrium under the stricter rule.

Thus, assume that a competitive equilibrium exists under the stricter rule $\nu_{1}$ in which the contract offered to the $h$-recipient is $(\bar{k}, \bar{I})$, and in which the contract offered to the $l$-recipient is $C_{l}^{1}=\left(\left(\tilde{k}_{1}, \tilde{I}_{1}, \tilde{p}_{1}\right)\right.$. Denote this competitive equilibrium allocation $\tilde{A}\left(\nu_{1}\right)$. Under a more lenient rule $\nu_{2}$, the insurer can offer the same contract $(\bar{k}, \bar{I})$ to the $h$-recipient and a contract $C_{l}^{2}=\left(\left(\tilde{k}_{1}, \tilde{I}_{1}, p_{2}\right)\right.$ to the $l$-recipient that audits with a higher probability $p_{2}>\tilde{p}_{1}$. $p_{2}$ is set so as to exactly compensate for the lower sanction $\left(\nu_{2}>\nu_{1}\right)$, i.e. such that the truth-telling constraint is exactly met also under the $C_{l}^{2}$ contract. Denote this allocation $A\left(\nu_{2}\right)$. For it to be possible to set a $p_{2}$ which exactly meets the truth-telling constraint, it must be the case that the more lenient rule induces truth-telling when auditing is certain to occur. When the truth-telling constraint is exactly met under both $C_{l}^{1}$ and $C_{l}^{2}$, the $h$-recipient is indifferent between the $C_{l}^{2}$ and the $C_{l}^{1}$ contract. Critically, this in turn implies that also the $l$-recipient is indifferent between $C_{l}^{2}$ and $C_{l}^{1}$. This is so because the $l$-recipient is either high risk (with probability $\alpha$ ) or low risk (with probability $1-\alpha$ ). If she is high risk her utility will be same as the utility which the $h$-recipient would derive from choosing the contract intended for the low risk. As just mentioned, this utility is the same under $C_{l}^{2}$ as under $C_{l}^{1}$. If she is low risk, her expected utility is also clearly the same under $C_{l}^{2}$ as under $C_{l}^{1}$, since both contracts pay the same when there is no misrepresentation, and there can be no misrepresentation when the l-recipient is low risk. When both the $h$-recipient and the $l$-recipient are as well off in the allocation $A\left(\nu_{2}\right)$ as in the allocation $\tilde{A}\left(\nu_{1}\right)$, then if the insurer obtains a higher expected profit by $C_{l}^{2}$ contract than by the $C_{l}^{1}$ contract, the $A\left(\nu_{2}\right)$ allocation Pareto-dominates the $\tilde{A}\left(\nu_{1}\right)$ allocation. To show that the insurer in fact obtains a higher expected profit from the $C_{l}^{2}$ contract than from the $C_{l}^{1}$ contract when $c$ is sufficiently small, we demonstrate that this is so when $c=0$. By continuity, it must then also hold when $c$ is sufficiently small. The key to understanding that the expected profit to the insurer is higher under the more lenient rule is to realise that the expected 
profit is higher when the expected pay-out to the $l$-recipient is lower. The expected payout must be higher on the $C_{l}^{1}$ contract than on the $C_{l}^{2}$ contract because the $h$-recipient is indifferent between the two contracts, and the variance of the $C_{l}^{1}$ contract is higher since $\nu_{2}>\nu_{1}$. When the variance is higher, this must be compensated by a higher expected pay-out (to the $h$-recipient and hence also to the $l$-recipient who may be high risk). Hence, the insurer earns a higher average profit under the $C_{l}^{2}$ contract. Thus, when $c=0$, it is possible to make the insurer better off under the $C_{l}^{2}$ contract than under the $C_{l}^{1}$ contract while maintaining the expected utility of both the $h$-recipient and the $l$-recipient. Hence, there exists a feasible allocation under the $\nu_{2}$ rule, which Pareto-dominates the equilibrium allocation under the $\nu_{1}$ rule. Finally, this is shown in Appendix $\mathrm{C}$ to imply that there exists an equilibrium under the $\nu_{2}$ rule and that it Pareto-dominates the equilibrium under the $\nu_{1}$ rule.

In short, the reason that frequent auditing and a low sanction for misrepresentation is superior to infrequent auditing and a high sanction is that the frequent auditing deters through an income transfer from the insured to the insurer, which leads to a lower premium, whereas infrequent auditing and a high sanction deters partly due to the income transfer and partly due to the expected utility loss which a high sanction imposes on a risk averse policy-holder; the latter involves no gain to the insurer as does an income transfer.

The proposition is illustrated by misstatement of age in life insurance contracts for which most state statutes in the US apply the pro rata rule. Jerry and Richmond ((2007) p. 78283) explain that the pro rata rule applies to such error but not more generally in the areas of liability and property insurance, because it is 'easier to discover the misrepresentation for the misstatement of age'.

Let us now consider the case of high auditing costs to which the same logic can be applied with the opposite result.

Proposition 2. When the insurer can commit to an auditing strategy and the cost of auditing is sufficiently high, a stricter rule is weakly Pareto-superior to a more lenient rule

The idea of the proof is this: Consider an equilibrium with auditing under the rule $\nu_{2}$ and an allocation under the stricter rule $\nu_{1}$ such that the truth-telling constraint is exactly met, which it will be at a lower level of auditing since $\nu_{1}<\nu_{2}$. As shown above, both the $l$-recipient and the $h$-recipient are as well off in this allocation as in the equilibrium. The net revenue earned by the insurer is higher under the stricter rule when:

$$
\tilde{p}_{2}\left(\alpha \pi_{h}\left(\tilde{I}-\nu_{2}\right)-\hat{\pi} c\right)<\tilde{p}_{1}\left(\alpha \pi_{h}\left(\tilde{I}-\nu_{1}\right)-\hat{\pi} c\right)
$$

which must be fulfilled when $c$ is sufficiently high. As shown in more detail in Appendix $\mathrm{D}$, this implies that when there exists a competitive equilibrium under the more lenient rule, there also exists a competitive equilibrium under the the stricter rule, and the latter Pareto-dominates the former.

The two propositions allow a ranking of rules of different strictness in cases when the cost of auditing is either high or low. For example, as explained above, the pro rata rule is not as strict as the contribute-to-the-loss rule, and both rules meet the truth-telling constraint 
when auditing is certain. So according to the two propositions the pro rata rule is superior to the contribute-to-the-loss rule when the cost of auditing is sufficiently low, while the contribute-to-the-loss rule is superior when the cost of auditing is sufficiently high.

The analysis applies also to the recovery rule which does not deter when auditing is certain. A rule that can never deter is not optimal under the assumptions of the model, since the rule will force the insurer to separate the types through the level of coverage on the $C_{l}$ contract only, and such separation can always be achieved by the insurer under any rule.

As for the role of the informativeness of the signal, we can replicate the result of Dixit and Picard (2003) that the common law rule is the efficient rule when the signal is sufficiently informative. Intuitively, when the $l$-recipient can be almost certain that the signal is trustworthy, auditing of type can induce truth-telling without imposing a risk on her.

Proposition 3. When the insurer can commit to an auditing probability, and auditing comes at a cost, the common law rule is optimal when the signal is sufficiently informative

The proof is in Appendix E.

7.2. When the insurer cannot commit to an auditing probability. It has been assumed so far that the insurer can commit to a level of auditing. However, establishing a reputation for auditing may be difficult, even if the insurer covers an individual in more than one area of insurance (car-insurance, life insurance, home-insurance, liability insurance, etc.). As mentioned, Picard (2009) analysed this case of non-commitment in which the insurer chooses the auditing probability in an ex-post optimal manner. Picard analysed the common law rule and considered the case in which the insured is certain about her type. We now extend his analysis to the case in which the $l$-recipient is uncertain about her type. Picard assumed that the cost of auditing is a constant $c$; we shall first consider this case and then that of a convex cost function.

7.2.1. A constant cost of auditing. If auditing must be optimal ex-post, it may be that a strict rule is necessary for auditing to occur at all. Auditing will not occur in a separating equilibrium if the rule $\nu$ is such that $\beta(\bar{I}-\nu)<c$, where $\beta$ is the probability that the insured is high risk conditional on the occurrence of an accident and on the insured being a $l$-recipient. Note that the insurer may increase his own incentive to audit by setting $I=\bar{I}$. When auditing is profitable ex post, i.e. if $\beta(I-\nu)>c$, it will always occur, in which case there is no reason to set $I$ below $\bar{I}$ because the truth-telling constraint will then not be binding. However, no auditing may be preferable to certain auditing:

Proposition 4. When insurers cannot commit to an auditing strategy, a lenient rule that leads to no auditing may be weakly Pareto-superior to a strict rule that leads to auditing with certainty, when the insured is sufficiently risk averse in the relevant range of income

Proof: Let $\nu_{1}$ be a rule for which there will always be auditing in the separating equilibrium since $\beta\left(\bar{I}-\nu_{1}\right)>c$, and let $\nu_{2}$ be a rule for which there will never be auditing, since $\beta\left(\bar{I}-\nu_{2}\right)<c$. Denote the equilibrium under rule $\nu_{1}$ by $\left(\tilde{k}_{1}, \tilde{I}_{1}, \tilde{p}_{1}=1\right)$. We can assume that the truth-telling constraint is not binding under rule $\nu_{1}$ when auditing is certain to 
occur (the rule is strict enough for this to be the case) in which case $\tilde{I}_{1}=\bar{I}$, since there is no reason to set $I$ lower than $\bar{I}$ when the truth-telling constraint is met through auditing. Denote the equilibrium under $\nu_{2}$ by $\left(\tilde{k}_{2}, \tilde{I}_{2}, \tilde{p}_{2}=0\right)$, where $\tilde{p}_{2}=0$ by the assumption that $\beta\left(\bar{I}-\nu_{2}\right)<c$. Let $\nu_{1}$ be such that $\nu_{1}<L-\tilde{k}_{2}$, hence $U\left(w_{0}-L+\nu_{1}\right)<U\left(w_{0}-\tilde{k}_{2}\right)$. Again, this is not restrictive; for most rules, the insured is worse off if an accident occurs and she is found to have misrepresented than when she only has to pay the premium on a no-auditing insurance. The expected utility of the $l$-recipient is greater under the rule $\nu_{2}$ than under the rule $\nu_{1}$ when

$$
(1-\hat{\pi}) U\left(w_{0}-\tilde{k}_{2}\right)+\hat{\pi} U\left(w_{0}-L+\tilde{I}_{2}\right)>\hat{\pi} \beta U\left(w_{0}-L-\nu_{1}\right)+\hat{\pi}(1-\beta) U\left(w_{0}-L+\bar{I}\right)
$$

Since $U\left(w_{0}-L+\nu_{1}\right)<U\left(w_{0}-\tilde{k}_{2}\right)$, this is fulfilled when $U\left(w_{0}-L-\nu_{1}\right)$ is sufficiently negative, i.e. when the insured is sufficiently risk averse in the region of income involving the accident loss and the insufficient indemnity $\nu_{1}$.

The incontestability clause in life insurance illustrates the proposition. This clause, which some period of time after signature bars the company from a defence claiming misrepresentation, was introduced in the mid-nineteenth century by an American insurance company in response to demand from customers who, as described by Goodman (1968), wanted to avoid the possibility of rescission in case of inadvertent mistakes. Goodman mentions that insurers sometimes acted opportunistically, construing minor misrepresentations as 'material'. Thus, in a sense, the ex-post optimal level of auditing was deemed too high by policy-holders. The clause is common today in the US; in some cases, however, reserving the right of the insurer to rescind the contract in case of fraud. The clause then effectively allows full indemnification for innocent and negligent misrepresentation, much like the German rule, some time after signature.

Naturally, there are circumstances in which the rule should be strict enough to induce auditing. This is e.g. the case if $\alpha$ and $c$ are both small. It may then take a low $\nu$ to induce auditing, and certain auditing can then be worthwhile because it separates at low cost both in terms of the auditing itself and in terms of the risk imposed on the $l$-recipient. Note that when auditing should be induced, the rule should be no stricter than that which exactly induces truth-telling; a rule that is stricter imposes unnecessary risk on the $l$-recipient. This is an example that a rule of intermediate strictness can be optimal.

It may be that no rule can induce auditing in a separating equilibrium, namely when $\beta(\bar{I}-0)<c$. In that case, the choice is between rules that all yield zero auditing if we consider only pure strategy equilibria. As shown by Picard (2009), it is then worth considering mixed-strategies which lead to the concept of a semi-separating equilibrium. A semi-separating equilibrium can be thought of as a situation where both the insurer and the insured are uncertain about what the other will do. It can then be optimal for the insurer to audit, if he suspects that a fraction of the $h$-recipients will choose the $C_{l}$ contract. Two cases must then be distinguished. In the first, auditing is not part of the equilibrium and separation occurs through the deductible only. As argued above, such may be the case when $c$ is so high that auditing cannot compete with the deductible as an instrument of separation. Then the rule of misrepresentation obviously does not matter. In the second, it is worth using representation as an instrument of separation even though $\beta \bar{I}<c$. In the 
latter case, i.e. when it is worth using representation as an instrument in a semi-separating equilibrium, it will now be shown that the common law rule is the most efficient rule.

Proposition 5. If the insurers cannot commit to an auditing strategy and $\beta \bar{I}<c$ such that there will be no auditing in a separating equilibrium, the common law rule is weakly Pareto-superior to any other rule

The proof is in Appendix F. Interpreting the result, if the rule is lenient, the fraction of $h$-recipients which the insurer thinks will choose the $C_{l}$ contract will have to be high, since an audit is then costly in proportion to the income it generates. However, when the fraction is high, the insurers will lose on the many $h$-recipients who choose the $C_{l}$ contract, which means that the premium will have to be raised on the $C_{l}$ contract for the insurers to make nonnegative profits. The $l$-recipients are hence worse off the more lenient the rule, while the $h$-recipients always achieve the expected utility of the $C_{h}$ contract (otherwise they would not employ a mixed strategy) and the insurers always obtain zero profits. This implies that the strictest rule is the Pareto-optimal rule.

7.2.2. Convex auditing costs. We have assumed so far that the cost of auditing is fixed. However, convexity may be the more realistic assumption. Consider e.g. the choice for the insurer of how many auditors to hire. If he hires only a few, they will be able to pursue only obvious signs of misrepresentation. A police report may e.g. contain evidence that a building has been burglarised before, contrary to the owner's representation. If the insurer hires more auditors, they can pursue also less promising leads, increasing the probability that the insured will effectively be audited but at an increasing marginal cost.

If $c(p)$ is convex, i.e. if $c^{\prime}(p) \geq 0$ and $c^{\prime \prime}(p)>0$, and if $c(0)=0$ and $c^{\prime}(0)=0, p$ will ex post be set according to the first-order condition: $\beta(\tilde{I}-\nu)=c^{\prime}(p)$. A stricter rule will then create a higher level of auditing. It is clear from the results above that a very strict rule may then be too strict in that it imposes both a high sanction and a high auditing probability, while a very lenient rule may then be too lenient because it imposes a low sanction and low auditing probability. More generally, as above, the cost function $c(p)$, the likelihood of inadvertent mistakes (closely associated with the parameter $\beta$ ) and the risk aversion of the insured together will determine the optimal rule. Thus, consider e.g. the case where $c^{\prime}(p)$ is low and only slightly increasing over a wide interval. If $\beta$ is high, there will then be a high level of auditing if the rule is strict because a strict rule means that $\tilde{I}-\nu$ is high. A high level of auditing and a strict rule may together more than fulfil the truth-telling constraint if the insured is very risk averse. That may be costly for the $l$-recipient because $\beta$, i.e. the likelihood for the $l$-recipient of being found to have misrepresented, is high. A more lenient rule may still fulfil the truth-telling constraint and then be preferable to the $l$-recipient. On the other hand, a very lenient rule may create very little auditing, especially if $\beta$ is low, which may be inefficient if auditing can be achieved at a rather low cost and if auditing is a cost-effective way of separating the types because $\beta$ and $c(p)$ are both low. 


\section{Discussion}

This section discusses the extent to which the analytical results depend on the assumptions made:

The model assumes that insurers and the insured know the legal rule of misrepresentation. This may be a realistic assumption as far as insurers are concerned, but may be strained in the case of the insured, although insurers sometimes instruct their agents to notify the insured about the consequences of misrepresentation. Naturally, the incentive rationale of a strict rule is weakened to the extent that the strict rule is not known by those who apply for insurance. Yet, a strict rule may lower the extent of cross-subsidisation of the high risks by the low risks if the equilibrium involves some degree of pooling due to ignorance of the rule. Lowering cross-subsidisation may keep low risk types in the market. This is explored in Gravelle (1991).

It has been assumed that the insured will misrepresent when this yields a higher expected utility; this utility does not incorporate a moral cost of misrepresentation. One would expect the optimal rule to be more lenient, the more averse people are to lying (Lundquist et al., 2009).

The model assumes, in the line of Rothschild and Stiglitz (1976), that insurers can screen by offering price-quantity pairs. This presupposes that the insured cannot take up insurance policies with more than one insurer to undo the quantity-constraint. However, for some kinds of insurances, the policy-holders can in fact do so, as documented by Cawley and Philipson (1999) for life-insurance. If screening through quantity-rationing or representation is not possible, the insurer may have to offer the same premium to all policy-holders, and then asymmetry of information creates inefficiency by the high risks purchasing too much insurance and the low risks purchasing too little, since the low risks subsidise the high risk. In that setting, similar trade-offs arise as analysed in this article.

The analysis assumed that the policy-holder does not incur a cost in producing the information which the insurer asks for. However, it is conceivable that a strict rule of misrepresentation will make the insurer ask for more costly information, e.g. for more health tests, since the information can be used to greater effect under a strict rule. This relates to Crocker and Snow (1986) who showed that allowing categorisation of risk according to e.g. health risks may not be optimal when it is costly for the insured to produce the information. ${ }^{28}$ Whether this implies that a lenient rule may be preferable to a strict rule of misrepresentation is beyond the scope of this article. ${ }^{29}$

Conceivably, rules of misrepresentation may affect the insurer's broader strategies. The insurer may e.g. search for misrepresentation that can be construed artificially as material among the sometimes many answers provided by the insured, or he may benefit from a superior bargaining position, e.g. when the insured is in urgent need of indemnification. As mentioned, such forms of opportunism are said to have occurred in the domain of life

\footnotetext{
${ }^{28}$ See, however, Rothschild C. (2011) for a contradictory view which assumes that the government can provide insurance in an optimal manner.

${ }^{29}$ Note that this issue is linked also to the analysis of rules of disclosure of information prior to sale as addressed e.g. by Shavell (1989).
} 
insurance (Goodman (1968)), and one would expect a strict rule to raise the returns to such business practices. Moreover, the strictness of the rule may affect the insurer's choice between auditing ex-ante before approving the applicant (so called pre-claim underwriting) and auditing ex-post (post-claim underwriting). Although post-claim underwriting is cheaper in that it only occurs in the event of an accident, pre-claim underwriting may be preferable, if the risk to the insured of inadvertent misrepresentation is significant (or if post-claim underwriting is subject to the form of abuse just mentioned).

\section{Conclusion}

Rules of misrepresentation in insurance contract law differ significantly between jurisdictions. In civil law, the rules are significantly more lenient towards the insured than in common law. The economic literature has tended to defend the strict common law rule, because it allows the insurer to more easily separate different types of risk. This view may be thought to hold even when applicants for insurance may misrepresent by mistake, since the insurer can deter intentional misrepresentation through a lower level of auditing when the rule is strict, and a lower level of auditing decreases both the risk to the honest insured and the expected auditing costs. However, this article demonstrates that a rule more lenient than that of common law may be optimal both when the insurer can and when he cannot commit to a level of auditing. When commitment is possible, frequent auditing under a lenient rule deters mainly through the prospect of an income transfer from the insured to the insurer, which raises the insurer's income and thereby indirectly benefits the insured through a lower premium, while infrequent auditing under a strict rule deters intentional misrepresentation through a lowering of the insured's expected utility with no attending benefit to the insurer. Therefore, when the cost of auditing is sufficiently low, the more lenient of two rules is optimal as long as it deters intentional misrepresentation when auditing is certain to occur. When commitment is not possible, a strict rule of misrepresentation may make it worthwhile for the insurer to audit often even in a separating equilibrium if inadvertent misrepresentation is frequent. Auditing may then be excessive. A lenient rule may lead to a low level of auditing when auditing costs are a convex function of the auditing probability, but a low level of auditing may be sufficient to induce truth-telling when the insured is highly risk averse. In general, the optimal rule depends on the cost of auditing, on whether the insured can commit to an auditing strategy, on the degree of risk aversion of the insured and on the likelihood of inadvertent misrepresentation.

\section{REFERENCES}

The American Law Institute. May 2013. Tentative Draft No. 1 (Principles 2013). See https://www.ali.org/publications/show/liability-insurance/

The American Law Institute. April 2015, Restatement of the Law. Liability Insurance, Discussion Draft. 
Barnes, B., 2010. Against Insurance Rescission, 120 YALE L.J. 328.

Cawley, J., and Philipson, T., 1999, An Empirical Examination of Information Barriers to Trade in Insurance, American Economic Review, 89(4): 827-846.

Crocker, K.J and Snow, A., 1986. The Efficiency Effects of Categorical Discrimination in the Insurance Industry. Journal of Political Economy. 94, 321-344.

Danish Insurance Contract Act, 1930. Forsikringsaftaleloven. Translated here: http: //www.aida.org.uk/pdf/Danish\%20Insurance\%20Contract\%20Act\%20-\%20English.pdf

Derrig, R. A., (2002). Insurance Fraud. Journal of Risk and Insurance, 69: 271-287.

Dixit, A., 2000. Adverse selection and insurance with Uberima Fides. In: Hammond, P.J. and Myles, G.D. (Eds), Incentives, Organization and Public Economics: Essays in Honor of Sir James Mirrlees. Oxford University Press, Oxford.

Dixit, A. and Picard, P., 2003. On the role of good faith in insurance contracting. In: Arnott, R., Greenwald, B., Kanbur, R., and Nalebuff, B. (Eds), Economics for an Imperfect World: Essays in Honor of Joseph Stiglitz, MIT Press, Cambridge, MA, 17-34.

German Insurance Contract Act (2008) in translation: http://www gesetze-im-internet . de/englisch_vvg/englisch_vvg.html.

Gravelle, H., 1991. Insurance law and adverse selection, International Review of Law and Economics, Vol. 11, No. 1, pp 23-45.

Heiss, H., 2013. Proportionality in the New German Insurance Contract Act 2008. Erasmus Law Review, Vol. 5, No. 2. Available at SSRN: http://ssrn. com/abstract=2209758.

Goodman, O. R. 1968. Public Policy and the Age of Incontestable Clauses in Life Insurance Contracts, The Journal of Risk and Insurance 35: 515-535.

Jerry, R. and Richmond D. 2007. Understanding Insurance Law. Lexis Nexis, Newark, NJ.

Lundquist, Tobias, Tore Ellingsen, Erik Gribbe and Magnus Johannesson. 2009. The aversion to lying, Journal of Economic Behavior \& Organization 70: 81-92,

Picard, P., 2009, Costly risk auditing without commitment in competitive insurance markets, Games and Economic Behavior, 66, 893-919.

Principles of European Insurance Contract Law. Oktober 2009. Juergen Basedow et al. 
Sellier European Law Publisher.

Rea S. Jr., 1993. The economics of insurance law, International Review of Law and Economics, Vol. 13, Iss. 2, 145.

Rothschild, M. and Stiglitz, J., 1976. Equilibrium in competitive insurance markets: An Essay on the economics of imperfect information, The Quarterly Journal of Economics, Vol. 90, No. 4, 629-649.

Ruehl, G., (2006) Common law, civil law, and the single European market for insurances, The International and Comparative Law Quarterly, Vol. 55, No. 4 879-910.

Shavell, S., (1994). Acquisition and Disclosure of Information Prior to Sale. Rand Journal of Economics, 25, 20-36.

Tarr, A. and Tarr, J.A., 2001. The insured's non-disclosure in the formation of insurance contracts: A comparative perspective. The International and Comparative Law Quarterly, Vol. 50, No. 3, 577-612.

\section{ApPEndix A. Notation}

$h$-risk: an individual with a high risk of accident.

$l$-risk: an individual with a low risk of accident.

$\lambda$ : the fraction of high-risk individuals in the population.

$1-\lambda$ : the fraction of low-risk individuals in the population.

$q$ : probability that someone who is a high risk will receive the low risk signal.

$\pi_{h}$ : probability of an accident for the $h$-risk.

$\pi_{l}$ : probability of an accident for the $l$-risk; $\pi_{h}>\pi_{l}$.

$U(w)$ : the utility function for any applicant. $U$ is strictly concave.

$w_{0}$ : the initial wealth of any applicant.

$l$-recipient: recipient of the low risk signal.

$h$-recipient: recipient of a high risk signal.

$\alpha=\frac{\lambda q}{\lambda q+(1-\lambda)}$ : the probability that the recipient of the low risk signal is nevertheless $h$-risk. $\hat{\pi}=\alpha \pi_{h}+(1-\alpha) \pi_{l}$ : The risk of accident when one has received the low risk signal.

$\beta=\frac{\lambda q \pi_{h}}{(\lambda q+(1-\lambda)) \hat{\pi}}=\frac{\alpha \pi_{h}}{\hat{\pi}}$ : The probability of being $h$-risk when having received the low risk signal, and when an accident has occurred..$^{30}$

$k$ : the premium of the contract intended for the $l$-recipient.

$I$ : the net indemnity of the contract intended for the $l$-recipient, provided the insured is not found to have misrepresented. The pay-out is hence $I+k$.

$\nu$ : the net indemnity for the $l$-recipient, if the $l$-recipient is found to have misrepresented.

${ }^{30}$ This expression is derived in Dixit and Picard (2003). 
The pay-out, which is set by the legal rule, is hence $\nu+k$.

$p$ : the probability of investigation of type when a claim is raised.

$C_{l}=(k, I, p)$ : contract intended for the $l$-recipient.

$\tilde{C}_{l}=$ equilibrium contract for the $l$-recipient

$k^{h}$ : the premium of the contract intended for the $h$-recipient.

$I^{h}$ : the net indemnity of the contract intended for the $h$-recipient

$C_{h}=\left(k^{h}, I^{h}\right)$ contract intended for the $h$-recipient

$A=\left(C_{h}, C_{l}\right)$ : An allocation consisting of two contracts, one for each type

$\bar{k}=\pi_{h} L$

$\bar{I}=L-k$

$\tilde{C}_{h}=$ equilibrium contract for the $h$-recipient

$\sigma_{l}$ : the probability with which the $l$-recipient chooses the $C_{l}$ contract.

$\sigma_{h}$ : the probability with which the $h$-recipient chooses the $C_{h}$ contract.

\section{Appendix B. Properties of the equilibrium CONTRACt for the $l$-Recipient}

It will be shown that if there exists an equilibrium, it will be one of under-insurance, i.e. the pay-out $I+k$ will be lower than the loss, when and only when:

$$
\frac{\left(1-\pi_{h}\right)}{(1-\hat{\pi})}<\frac{\pi_{h}(1-p)}{\hat{\pi}(1-p \beta)}
$$

The claim can proved by showing that any stationary point of the Lagrange function must be one of under-insurance when the inequality holds. Omitting the Lagrange multipliers associated with (4), the Lagrange function is given by

$$
\begin{array}{r}
\mathcal{L}=(1-\hat{\pi}) U\left(w_{0}-k\right)+\hat{\pi} \beta p U\left(w_{0}-L+\nu\right)+\hat{\pi}(1-\beta p) U\left(w_{0}-L+I\right) \\
+\lambda_{1}\left(k-\alpha \pi_{h} p(\nu+k)-\left((1-\alpha) \pi_{l}+(1-p) \alpha \pi_{h}\right)(I+k)-\hat{\pi} p c\right) \\
+\lambda_{2}\left(U\left(w_{0}-\bar{k}\right)-\left(\left(1-\pi_{h}\right) U\left(w_{0}-k\right)+\pi_{h} p U\left(w_{0}-L+\nu\right)+\pi_{h}(1-p) U\left(w_{0}-L+I\right)\right)\right.
\end{array}
$$

where $\lambda_{1}>0$ and $\lambda_{2}>0$.

$\frac{\delta \mathcal{L}}{\delta k}=0$ yields

$$
U^{\prime}\left(w_{0}-k\right)=\frac{\lambda_{1}(1-\hat{\pi})}{1-\hat{\pi}-\lambda_{2}\left(1-\pi_{h}\right)}
$$

while $\frac{\delta \mathcal{L}}{\delta I}=0$ yields

$$
U^{\prime}\left(w_{0}-L+I\right)=\frac{\lambda_{1}\left(\hat{\pi}-\alpha p \pi_{h}\right)}{\hat{\pi}(1-\beta p)-\lambda_{2} \pi_{h}(1-p)}
$$

There is under-insurance when $I+k<L$, i.e. when $w_{0}-k>w_{0}-L+I$, which means that

$$
\frac{\lambda_{1}(1-\hat{\pi})}{1-\hat{\pi}-\lambda_{2}\left(1-\pi_{h}\right)}<\frac{\lambda_{1}\left(\hat{\pi}-\alpha p \pi_{h}\right)}{\hat{\pi}(1-\beta p)-\lambda_{2} \pi_{h}(1-p)}
$$


Note that both sides of this inequality are non-negative, since they are equal to a derivative of the utility function. By inverting both fractions, and using that $\beta=\alpha \pi_{h} / \hat{\pi}$ this leads to the condition that

$$
\frac{(1-\hat{\pi})-\lambda_{2}\left(1-\pi_{h}\right)}{1-\hat{\pi}}>\frac{\hat{\pi}(1-\beta p)-\lambda_{2} \pi_{h}(1-p)}{\hat{\pi}(1-\beta p)}
$$

which is equivalent to

$$
1-\frac{\lambda_{2}\left(1-\pi_{h}\right)}{(1-\hat{\pi})}>1-\frac{\lambda_{2} \pi_{h}(1-p)}{\hat{\pi}(1-\beta p)}
$$

which again is equivalent to

$$
\frac{\left(1-\pi_{h}\right)}{(1-\hat{\pi})}<\frac{\pi_{h}(1-p)}{\hat{\pi}(1-p \beta)}
$$

Conversely, when this inequality holds, $I<L-k$ in any stationary point of the Lagrangian. If this is so, the condition that $I$ cannot exceed $L-k$, imposed in (4), cannot be binding, for it were binding the unrestricted maximum would lie at a point where $I>L-k$, i.e. there would be a stationary point of the Lagrangian without (4) for which $I>L-k$. It also follows that if

$$
\frac{\left(1-\pi_{h}\right)}{(1-\hat{\pi})} \geq \frac{\pi_{h}(1-p)}{\hat{\pi}(1-p \beta)}
$$

there will be over-insurance in equilibrium if it were not for constraint that $I \leq L-k$. This implies that with the constraint, there will then be full insurance.

\section{Appendix C. Proof of Proposition 1}

We compare two rules, $\nu_{1}$ and $\nu_{2}$, where $\nu_{1}$ is the stricter rule, $\nu_{1}<\nu_{2}$. We first prove that when the insured is risk averse, the cost of auditing is sufficiently small, and there exists a competitive equilibrium under the stricter rule $\nu_{1}$, then there exists a feasible allocation under the rule $\nu_{2}$, which Pareto-dominates the equilibrium allocation under the rule $\nu_{1}$. We then show this to imply that there also exists an equilibrium allocation under the $\nu_{2}$ and that it Pareto-dominates the equilibrium allocation under the $\nu_{1}$ rule.

Let the equilibrium under the $\nu_{1}$ rule be given by the contract offered to the $l$-recipient: $C_{l}^{1}=\left(\left(\tilde{k}_{1}, \tilde{I}_{1}, \tilde{p}_{1}\right)\right.$, and by the contract $(\bar{k}, \bar{I})$ offered to the $h$-recipient. Under the less strict rule, $\nu_{2}$, the insurer can offer the same contract to the $h$-recipient, i.e. $(\bar{k}, \bar{I})$, and the contract $C_{l}^{2}=\left(\tilde{k}_{1}, \tilde{I}_{1}, \tilde{p}_{2}\right)$ to the $l$-recipient, where $\tilde{p}_{2}$ is set higher than $\tilde{p}_{1}$ such that the truth-telling constraint is exactly met although $\nu_{1}<\nu_{2}$. To show that this is a feasible allocation under the rule $\nu_{2}$, we first show that it not only fulfils the truth-telling constraint (which it does by construction) but also makes both the $l$-recipient and the $h$-recipient as well off as the equilibrium allocation under the $\nu_{1}$ rule. This is obvious for the case of the $h$-recipient since she receives the same contract in the two allocations. That the $l$-recipient is as well-off under $C_{l}^{2}$ as under $C_{l}^{1}$ when the truth-telling constraint is exactly met under both allocations can be seen as follows. In general, when the contract offered to the 
$l$-recipient carries a premium of $k$ and pays out $I$ in case of no misrepresentation, the utility of the $l$-recipient can be written as $\alpha\left(U\left(w_{0}-\bar{k}\right)+(1-\alpha)\left(\left(1-\pi_{l}\right) U\left(w_{0}-k\right)+\pi_{l} U\left(w_{0}-L+I\right)\right.\right.$, because the $l$-recipient is either high risk, with probability $\alpha$ or low risk with probability $1-\alpha$. If she is high risk her utility will be same as the utility which the $h$-recipient would derive from choosing the contract intended for the low risk, which in equilibrium equals $U\left(w_{0}-\bar{k}\right)$ since the truth-telling constraint is binding in equilibrium. If she is low risk, her expected utility is $\left(1-\pi_{l}\right) U\left(w_{0}-\tilde{k}\right)+\pi_{l} U\left(w_{0}-L+\tilde{I}\right)$. In either case, she obtains the same expected utility under the $C_{l}^{2}$ contract as under the $C_{l}^{1}$ contract.

We now demonstrate that when the insured is risk averse and the cost of auditing is sufficiently low, the allocation that offers $C_{l}^{2}$ to the $l$-recipient and the contract $(\bar{k}, \bar{I})$ to the $l$-recipient under the $\nu_{2}$ rule yields a greater profit to the insurer than the equilibrium allocation under the $\nu_{1}$ rule. Since $I, k$ are the same in $C_{l}^{1}$ as in $C_{l}^{2}$, we shall refer to them as $\tilde{I}$, and $\tilde{k}$ for ease of exposition.

The profit to the insurer is higher under $C_{l}^{2}$ than under $C_{l}^{1}$ when:

$$
\begin{array}{r}
\tilde{k}-\alpha \pi_{h} \tilde{p}_{2}\left(\nu_{2}+\tilde{k}\right)-\left((1-\alpha) \pi_{l}+\left(1-\tilde{p}_{2}\right) \alpha \pi_{h}\right)(\tilde{I}+\tilde{k})-\hat{\pi} \tilde{p}_{2} c> \\
\tilde{k}-\alpha \pi_{h} \tilde{p}_{1}\left(\nu_{1}+\tilde{k}\right)-\left((1-\alpha) \pi_{l}+\left(1-\tilde{p}_{1}\right) \alpha \pi_{h}\right)(\tilde{I}+\tilde{k})-\hat{\pi} \tilde{p}_{1} c
\end{array}
$$

By a simple deletion of terms, this can be rewritten:

$$
\tilde{p}_{2}\left(\alpha \pi_{h}\left(\tilde{I}-\nu_{2}\right)-\hat{\pi} c\right)>\tilde{p}_{1}\left(\alpha \pi_{h}\left(\tilde{I}-\nu_{1}\right)-\hat{\pi} c\right)
$$

Below, we shall use this inequality to prove also Propositions 2 and 3.

We now show that 18$)$ is met when $c=0$, in which case it reduces to

$$
\tilde{p}_{2}\left(\tilde{I}-\nu_{2}\right)>\tilde{p}_{1}\left(\tilde{I}-\nu_{1}\right)
$$

Recall that $\tilde{p_{2}}$ is set so as to meet the truth-telling constraint, i.e.

$$
\left(1-\pi_{h}\right) U\left(w_{0}-\tilde{k}\right)+\pi_{h} \tilde{p}_{2} U\left(w_{0}-L+\nu_{2}\right)+\pi_{h}\left(1-\tilde{p}_{2}\right) U\left(w_{0}-L+\tilde{I}\right)=U\left(w_{0}-\bar{k}\right)
$$

and that the truth-telling constraint is exactly met also by the $C_{l}^{1}$ contract, i.e.

$$
\left(1-\pi_{h}\right) U\left(w_{0}-\tilde{k}\right)+\pi_{h} \tilde{p}_{1} U\left(w_{0}-L+\nu_{1}\right)+\pi_{h}\left(1-\tilde{p}_{1}\right) U\left(w_{0}-L+\tilde{I}\right)=U\left(w_{0}-\bar{k}\right)
$$

It follows from these two equations that

$$
\tilde{p}_{2} U\left(w_{0}-L+\nu_{2}\right)+\left(1-\tilde{p}_{2}\right) U\left(w_{0}-L+\tilde{I}\right)=\tilde{p}_{1} U\left(w_{0}-L+\nu_{1}\right)+\left(1-\tilde{p}_{1}\right) U\left(w_{0}-L+\tilde{I}\right)
$$

22 reveals the difference between $C_{l}^{1}$ and $C_{l}^{2}$. In the case of a loss to a $h$-risk, $C_{l}^{1}$ pays $\nu_{1}$ with probability $\tilde{p}_{1}$ and $\tilde{I}$ with probability $\left(1-\tilde{p}_{1}\right)$ while $C_{l}^{2}$ pays $\nu_{2}$ with probability $\tilde{p}_{2}$ and $\tilde{I}$ with probability $\left(1-\tilde{p}_{2}\right)$. Recall that $\nu_{1}<\nu_{2}$. The average pay-out of $C_{l}^{1}$ in the event of a loss is $\nu_{1} \tilde{p}_{1}+\tilde{I}\left(1-\tilde{p}_{1}\right)=\tilde{p}_{1}\left(\nu_{1}-\tilde{I}\right)+\tilde{I}$, while the average pay-out of of $C_{l}^{2}$ in the event of a loss is $\tilde{p}_{2}\left(\nu_{2}-\tilde{I}\right)+\tilde{I}$. Since the insured is risk averse, the average pay-out in the event of a loss to a $h$-risk must be greater under $C_{l}^{1}$ than under $C_{l}^{2}$ since the variance of the pay-out is greater under $C_{l}^{1}$ as $\nu_{1}<\nu_{2} \cdot{ }^{31}$ Hence, $\tilde{p}_{1}\left(\nu_{1}-\tilde{I}\right)>\tilde{p}_{2}\left(\nu_{2}-\tilde{I}\right)$ which means

\footnotetext{
${ }^{31}$ In general, it is easy to show using Jensen's inequality that when $\mathrm{U}$ is concave and $x_{1}<x_{2}$ and $p_{1} U\left(x_{1}\right)+\left(1-p_{1}\right) U(y)=p_{2} U\left(x_{1}\right)+\left(1-p_{2}\right) U(y)$ then $p_{1} x_{1}+\left(1-p_{1}\right) y>p_{2} x_{2}+\left(1-p_{2}\right) y$
} 
that $(19)$ is met, since it implies that $\tilde{p}_{1}\left(\tilde{I}-\nu_{1}\right)<\tilde{p}_{2}\left(\tilde{I}-\nu_{2}\right)$. Thus, 19 holds when $c=0$; by continuity it holds also when $c$ is sufficiently small.

This means that the $C_{l}^{2}$ contract offered to the $l$-recipient in combination with the contract $(\bar{k}, \bar{I})$ offered to the $h$-recipient Pareto-dominates the $C_{l}^{1}$ contract in combination with the contract $(\bar{k}, \bar{I})$. Note that while not an equilibrium contract under the rule $\nu_{2}$, the allocation which offers the contract $C_{l}^{2}$ to the $l$-recipient is feasible since it yields a non-negative profit to the insurer and respects the truth-telling constraint and the participation constraints. Consider the candidate for an equilibrium under the $\nu_{2}$ rule in which the profit of the insurer is competed down to zero; this is the separating equilibrium which maximises the expected utility of the $l$-recipient subject to the conditions that the insurer makes nonnegative profits, that the $h$-recipient's will tell the truth, and that the $h$-recipient will wish to participate. By definition, in this candidate for an equilibrium, the $l$-recipient must be better off than under the feasible allocation that offers the $C_{l}^{2}$ contract. Since the insurer and $h$-recipient are as well off in this candidate for an equilibrium as in the equilibrium under the $\nu_{1}$ rule, the candidate Pareto-dominates this equilibrium. It follows that the candidate is in fact an equilibrium, which can be seen as follows: The reason it may not be an equilibrium is that it may be optimal for an insurer to offer a pooling contract that makes both the $h$-recipient and the $l$-recipient at least as well off as under the candidate for an equilibrium, and which yields the insurer a higher profit (Rothschild-Stiglitz (1976, p. 637). However, if such a pooling contract could not eliminate the equilibrium under the $\nu_{1}$ rule (where an equilibrium was assumed to exist) it cannot eliminate the candidate for an equilibrium, since for it to do so it must make both the $h$-recipient and the $l$-recipient as well off, and the latter has become harder, since the $l$-recipient is better off in the candidate allocation under the $\nu_{2}$ rule than in the equilibrium allocation under the $\nu_{1}$ rule. Hence, since the insurer and $h$-recipient are both equally well off under the two equilibria, and the $l$-recipient is strictly better off in the equilibrium under rule $\nu_{2}$, the latter must Pareto-dominate the equilibrium under rule $\nu_{1}$ when $c$ is sufficiently small.

\section{Appendix D. Proof of PRoposition 2}

Proof: This proof reverses the proof of proposition 1. We can show that if there exists an equilibrium allocation $C_{l}^{2}=\left(\tilde{k}, \tilde{I}, \tilde{p_{2}}\right)$ under the rule $\nu_{2}>\nu_{1}$, it is Pareto-dominated by a feasible allocation $C_{l}^{1}=\left(\tilde{k}, \tilde{I}, p_{1}\right)$ under the $\nu_{1}$ rule, and then demonstrate that this implies that there exists an equilibrium under the $\nu_{1}$ rule and that it must Pareto-dominate the equilibrium under the $\nu_{2}$ rule. It is implicit that the contract $(\bar{k}, \bar{I})$ is always offered to the $h$-recipient. As in the proof of proposition $1, p_{1}$ is set to exactly meet the truthtelling constraint which implies that $p_{1}<\tilde{p_{2}}$ since $\nu_{1}<\nu_{2}$. It was shown above that if the two contracts both exactly meet the truth-telling constraint, then $\tilde{p_{2}}\left(\tilde{I}-\nu_{2}\right)>$ $p_{1}\left(\tilde{I}-\nu_{1}\right)$. However, it follows from $(18)$ that the profits to the insurer are nevertheless higher under $C_{l}^{1}$ if $c$ is sufficiently high. Since a feasible allocation under the $\nu_{1}$ rule therefore Pareto-dominates the equilibrium allocation under the $\nu_{2}$ rule when $c$ is sufficiently high, it follows from the same logic as that used to prove proposition 1 , that there exists 
a competitive equilibrium under the $\nu_{1}$ rule, and that the latter Pareto-dominates the competitive equilibrium under the $\nu_{2}$ rule.

\section{Appendix E. Proof of proposition 3}

When the signal is very informative, $\alpha$ is low. It follows from (18) that when $\alpha$ is sufficiently low the insurer's profit is higher under the stricter rule because of the higher cost of auditing under the more lenient rule. While revenues from auditing are higher under the more lenient rule, these revenues are small when there are few $l$-recipients who have received a false signal. It then follows from the logic behind the proofs of Proposition 1 and 2 that the strict rule Pareto-dominates a more lenient rule.

\section{Appendix F. Proof of Proposition 5}

Recall that $\tilde{C}_{l}, \tilde{C}_{h}$ are the equilibrium offers of contracts, and $\tilde{p}$ is the equilibrium level of auditing chosen ex-post. $\tilde{\sigma}_{l}(C)$ and $\tilde{\sigma}_{h}(C)$ are the equilibrium probabilities with which the two types choose the contracts intended for them as a function of any offer $C=\left(C_{l}, C_{h}\right)$. The proof proceeds as follows:

1. The perfect Bayesian Nash equilibrium is defined

2. A feasible allocation is defined

3. It is shown that an equilibrium is constrained Pareto-optimal

4. Two rules $\nu_{j}$ and $\nu_{i}$ are compared where $\nu_{i}+\delta \nu=\nu_{j}$, and where $\delta \nu$ is infinitesimal. It is shown that if there exists an equilibrium under the $\nu_{j}$ rule, there exists a feasible allocation under the slightly stricter $\nu_{i}$ rule which Pareto-dominates the equilibrium. This implies that the equilibrium under the $\nu_{i}$ rule Pareto-dominates the equilibrium under the $\nu_{j}$ rule since an equilibrium is constrained Pareto-optimal.

F.1. Definition of the perfect Bayesian equilibrium. The perfect Bayesian Nashequilibrium is defined by the following requirements:

(1) The equilibrium strategies $\left(\tilde{\sigma}_{l}(C), \tilde{\sigma}_{h}(C)\right)$ maximise the expected utilities of the $l$-recipient and the $h$-recipient for each given vector of offers $C$ from the $n$ insurers. The response of the insured must be optimal for every possible contract-offer by the insurers.

(2) $\tilde{C}=\left(\tilde{C}_{l}, \tilde{C}_{h}\right)$ maximises the expected profit of each insurer given the choice of the other insurers and given the optimal responses $\tilde{\sigma}_{l}, \tilde{\sigma_{h}}$.

(3) $\tilde{p}$ maximises $p \tilde{\mu}(\tilde{I}-\nu)-p c$ where the updated probability that a claimant is a $h$-risk, $\tilde{\mu}$, is given by

$$
\tilde{\mu}=\frac{\lambda(1-q)\left(1-\tilde{\sigma}_{h}\right) \pi_{h}+\lambda q \pi_{h}}{\lambda(1-q) \pi_{h}\left(1-\tilde{\sigma}_{h}\right)+\lambda q \pi_{h}+(1-\lambda) \pi_{l}}
$$

where $\tilde{\sigma}_{h}=\tilde{\sigma_{h}}(\tilde{C})$

In the numerator of the expression for $\mu$ are all those who have chosen the $\tilde{C}_{l}$ contract and are high risk. Thus, $\lambda(1-q)\left(1-\tilde{\sigma}_{h}\right) \pi_{h}$ is the number of individuals who are high risk $(\lambda)$, 
who receive a signal that they are $(1-q)$ but who nevertheless choose the contract for the $l$-recipients $\left(\left(1-\tilde{\sigma}_{h}\right)\right)$ and then have an accident $\left(\pi_{h}\right) . \lambda q \pi_{h}$ is the number of individuals who are high risk but who receive the good signal and therefore choose the $\tilde{C}_{l}$ contract and have an accident.

F.2. Definition of a feasible allocation. A feasible allocation $\left(C_{l}, C_{h}, \sigma_{l}, \sigma_{h}, p, \mu\right)$, where $\sigma_{l}$ is the probability with which the $l$-recipients choose the $C_{l}$ contract and $\sigma_{h}$ is the probability with which the $h$-recipients choose the $C_{h}$ contract, must fullfil the following requirements:

(1) $\left(\sigma_{l}, \sigma_{h}\right)$ maximise the expected utilities of the $l$-recipient and the $h$-recipient given $C_{l}$ and $C_{h}$ and given $p$.

(2) $C_{l}$ and $C_{h}$ both yield non-negative profits

(3) $p$ maximises $p \mu(I-\nu)-p c$ where the updated probability that a claimant is a $h$-risk, $\mu$, is given by

$$
\mu=\frac{\lambda(1-q)\left(1-\sigma_{h}\right) \pi_{h}+\lambda q \pi_{h}}{\lambda(1-q) \pi_{h}\left(1-\sigma_{h}\right)+\lambda q \pi_{h}+(1-\lambda) \pi_{l}}
$$

F.3. An equilibrium is constrained Pareto-efficient. It may be thought that an equilibrium must be constrained Pareto-optimal, since if there existed another $C_{l}$ contract than that of the equilibrium, which would bring about a Pareto-improvement, it would be profitable for an insurer to offer this contract. This logic worked perfectly when the insurers could commit to $p$, but as shown by Picard (2009, p. 907), in the case of non-commitment an equilibrium might get stuck in inefficiency if one injurer's deviation is met by a choice of $p$ by another injurer that renders the deviation unprofitable. As also shown by Picard, however, such a threat by another injurer would be a weakly dominated strategy, and can be disregarded by considering only trembling hand perfect equilibria. Then, according to Picard's Proposition 5 (p. 907), an equilibrium is constrained Pareto-optimal also when the insurers cannot commit to an auditing strategy. ${ }^{32}$

F.4. Comparison of two rules. We now compare two rules, $\nu_{j}$ and $\nu_{i}$ where $\nu_{i}+\delta \nu=\nu_{j}$, where $\delta \nu$ is infinitesimal. We show that if there exists an equilibrium under the $\nu_{j}$ rule, there exists a feasible allocation under the slightly stricter $\nu_{i}$ rule which Pareto-dominates the equilibrium. This implies that the equilibrium under the $\nu_{i}$ rule Pareto-dominates the equilibrium under the $\nu_{j}$ rule since an equilibrium is constrained Pareto-optimal (when weakly dominated strategies are ruled out). Since a slightly stricter rule is always preferable, we conclude that the common law rule is optimal.

Let the equation determining $\mu$ as a monotonous function of $\sigma_{h}$, determine the inverse function: $\sigma_{h}=\sigma_{h}(\mu)$ and let $\frac{\delta \sigma_{h}(\mu)}{\delta \mu}=\theta$.

\footnotetext{
${ }^{32}$ Picard's proof of this also applies to our setting. It relies on whether or not a shift to a more efficient contract will happen through competition, and the mechanics of this are unaffected by our assumption that $l$-recipients may make mistakes about their type
} 
We now demonstrate that when a semi-separating equilibrium, $\left.\left(\tilde{C}_{l}, \tilde{C}_{h}\right), \tilde{\sigma}_{l}, \tilde{\sigma}_{h}, \tilde{p}_{j}, \tilde{\mu}_{j}\right)$, exists under a rule $\nu_{j}$, it is Pareto-dominated by an allocation $\left(\left(C_{l}, C_{h}\right), \sigma_{l}, \sigma_{h}, p, \mu\right)$ under the $\nu_{i}$ rule, where:

(1) $C_{l}=\tilde{C}_{l}=(k, I)$

(2) $C_{h}=\tilde{C}_{h}=(\bar{k}, \bar{I})$

(3) $\sigma_{l}=\tilde{\sigma}_{l}$

(4) $\sigma_{h}=\tilde{\sigma}_{h}+\frac{\delta \sigma_{h}(\mu)}{\delta \mu} \frac{\delta \mu}{\delta \nu}=\tilde{\sigma}_{h}+\theta \frac{\mu}{I-\nu} \delta \nu$

(5) $\mu=\mu_{j}+\frac{\delta \mu}{\delta \nu} \delta \nu=\mu_{j}+\frac{\mu_{j}}{\left(I-\nu_{j}\right)} \delta \nu$

(6) $p$ is such that the $h$-recipient obtains the same utility from choosing the $C_{l}$ contract given $\nu_{i}$ and $p$ as she does from choosing the same contract given $\nu_{j}$ and $\tilde{p}_{j}$

We now show that the allocation is feasible. First, note that $p$ is such that the $h$-recipient is as well off as in the equilibrium from choosing the $C_{l}$ contract. This means that the $h$-recipient is indifferent between the $C_{l}$ contract and the $C_{h}$ contract, so $\sigma_{h}$ is an optimal choice by the $h$-recipient. This also means that the $l$-recipient is as well off in the allocation as in the equilibrium, since the $l$-recipient is $h$-risk with probability $\alpha$ and then obtains the same utility as the $h$-recipient from choosing the $C_{l}$ contract, and $l$-risk with probability $1-\alpha$ in which case she obtains the same utility from the $C_{l}$ contract as from the $\tilde{C}_{l}$ contract, as the two contracts are the same. When the $h$-recipient is indifferent between the $C_{l}$ contract and the $C_{h}$, any probability $\sigma_{h}$ is optimal. Hence, both the $l$-recipient and the $h$-recipient choose optimally in the allocation. Second, $\mu$ is such that the constraint $I-\nu_{i}=c$ is met, and $\sigma_{h}$ is such that $\mu$ can take this value. Then the insurer is indifferent in the choice of $p$, and a lower value $\left(p<\tilde{p}_{j}\right.$ that makes up for the lower $\nu(\nu<\tilde{n u}$ ), so as to render the $h$-recipient indifferent between the $C_{l}$ contract and the $C_{h}$ contract, is then optimal. Since the $C_{l}$ contract will be chosen by the $l$-recipient and the $C_{h}$ contract by the $h$-recipient, and $p$ is chosen optimally, the allocation is feasible.

We now show that the feasible allocation Pareto-dominates the equilibrium under the $\nu_{j}$ rule. Note that $p<\tilde{p}_{j}$ since $\nu_{i}<\nu_{j}$ and that $\tilde{\mu}<\tilde{\mu}_{j}$ by the constraint that $\tilde{\mu}\left(\tilde{I}-\nu_{i}\right)=c$. When $\mu$ is lower so it $\sigma_{h}$. Thus, since fewer $h$-recipients choose the $C_{l}$ contract, the profit on this contract is higher, since the insurer makes a loss when a $h$-risk chooses the $C_{l}$ contract (in the equilibrium, profits on the $\tilde{C}_{l}$ contract are zero). On the other hand, the fact that $p<p_{j}$ does not in itself affect the profit on the $C_{l}$ contract when the change in the rule is infinitesimal, since auditing yields as much income as it costs (by the condition that $\left(\tilde{I}-\nu_{i}=c\right)$. Hence, when the insurers choose the same contracts as in the equilibrium under the $\nu_{j}$ rule, profits on the $C_{l}$ go up, while leaving both the $h$-risk and the $l$-risk equally well off. Naturally, the profit on the $C_{h}$ is also unchanged. The equilibrium under the $\nu_{i}$ rule for which the profit on the $C_{l}$ contract is zero must yield a greater expected utility to the $l$-recipient than the feasible allocation, since the equilibrium under the $\nu_{i}$ rule cannot be Pareto-dominated by the feasible allocation since both are feasible and the equilibrium is constrained Pareto-optimal. This implies that the equilibrium under the $\nu_{i}$ rule Paretodominates the equilibrium under the $\nu_{j}$ rule; the $l$-recipient is better off and everyone else is equally well off. Hence, when for any given $\nu$, a small lowering of it creates greater efficiency, 
the optimal rule must be $\nu=0$. All this presumes that semi-separating equilibria exist. What may prevent a semi-separating from existing is that it may be optimal for an insurer to deviate by offering either the contracts that separate without auditing (i.e. only through the cover) or the profit-maximising pooling contract. However, it follows from the above that if a semi-separating equilibrium exists under the $\nu_{j}$ rule, it must also exist under the $\nu_{i}$ rule, since it will not be better for an insurer to deviate under the $\nu_{i}$ than to deviate under the $\nu_{j}$ rule. If semi-separating equilibria do not exist under either rule, the rule is irrelevant. In this sense the common law rule dominates other rules when $\tilde{\beta}(I-\nu)<c$. 